\title{
Determination of the ground resistance and distribution of potentials in grounding grids using FEM
}

\author{
J. A. Güemes ${ }^{1}$, F. Rodriguez ${ }^{1}$, J. M. Ruiz ${ }^{1}$, F. E. Hernando ${ }^{2}$ \\ ${ }^{1}$ Department of Electrical Engineering \\ E. U. I.T.I., University of the Basque Country \\ Plaza de la Casilla n ${ }^{\circ} 3,48012$ Bilbao (Spain) \\ phone + 34 946014363, fax +34 944441625, e-mail: iepgualj@lg.ehu.es \\ ${ }^{2}$ Instalaciones eléctricas Scorpio, S.A. \\ Nafarroa - Bloque 2, 48180 Loiu (Spain) \\ Phone + 34 944535033, fax + 34 944535356, e-mail: ies@sarenet.es
}

\begin{abstract}
Admitting the independence of the ground resistance in relation to the earth fault current, a new method for the calculation of the ground resistance using the finite element method to the resolution of solid models in $3 \mathrm{D}$, is presented in this paper. The results obtained by the method proposed were compared with those measured experimentally or determined, utilising other methods. Once ground resistance value and the earth fault current are known, the grid potential as well as the touch and step voltages are calculated. The main advantage of the method herein proposed is that it permits us to analyse symmetrical and non-symmetric grids in uniform soils with a layer o multiples layers. The method developed in this paper constitutes an industrial application, of acceptable results, to the calculation of the ground resistance.
\end{abstract}

\section{Keywords}

Ground resistance, grounding grids, earth fault current.

\section{Introduction}

The grounding resistance in electrical system is defined as $\mathrm{u} / \mathrm{i}$, where $\mathrm{u}$ is the electric potential of the grounding grid (or grounding electric pole), and i the earth fault current (current that flows into earth through the grounding grid).

The ground resistance value is an important technical parameter, which is connected with the safety of personnel and equipment. If the ground resistance is very high and an earth fault current happens, the personnel can be killed or injured and the equipment can be damaged.

The value of the ground resistance for a certain value of the grid current determines the value of dangerous voltages within or around the substation.

Grounding system of a substation or generating station is designed with the main objective of providing safety to personnel during an earth fault. The main purpose of a power system substation is to maintain reliable operation and provide protection for personnel and apparatus during fault conditions.
The basic configuration of a grounding grid is constituted by round steel rods forming two-dimensional grids (normally square or rectangular shape) and buried near the soil surface $(0.4-0.6 \mathrm{~m})$. When the grid is constituted by meshes and ground rods, the ground rods are only effective if a significant portion of their length is in contact with a low resistivity soil.

The grounding grids are, doubtless, the most important part of an electrical system from the point of view of the safety of the people and equipment. The reliability and availability of the electrical systems depends on the quality of the design and the construction of the grounding grids

The main aims of a grounding system are:

- The safety of the people against electrical risks by limiting the over-voltages to those they can be exposed, when faults in the electrical power systems are produced.

- The security and continuity of the electrical equipment, limiting the over-voltages that can appear in extreme conditions or in the case of incidents.

- The correct operation of the equipment and electrical protection devices, allowing the detection of faults and the selection of all actions oriented to disconnect the zones of the installation with earth fault current.

Calculation methods for modelling of grounding grids consider the following simplifying hypotheses:

- The soil is an infinite medium, plane, isotropic and stratified in layers.

- Electromagnetism laws are applicable to the calculation of the ground resistance and the grid potential.

- Grounding grid conductors are supposed lineal, interconnected and buried close to the ground surface. 
- The behaviour of the grounding grids at rated working frequency can be determined using electromagnetic fields analysis techniques for stationary fields (propagation time is ignored).

The different calculation methods, the ground resistance, are based on the determination of the potential or capacitance of the grounding electrode.

The calculation methods of grounding grids determine the ground resistance as well as the step and touch voltage, using different mathematical techniques, applying the hypotheses that allow us to model the real system in other theoretical of comparable results. These studies are developed generally for grounding grids that present symmetries and uniform soils [1] or stratified with two or more layers [2] - [6].

Recently, the study based in finite element method [7] has been used to calculate the ground resistance. The initial method was based in calculate the earth fault current (amperes) starting from a random grid potential, obtaining the ground resistance value as the quotient between voltage and the current. Once the ground resistance had been calculated, the finite element model was analysed again using the real grid potential (calculated as the product of the real fault current and the calculated ground resistance value), obtaining the potentials distribution in the model as well as the touch and step voltages.

This method presented certain difficulties in the selection of the model size (earth distance to be considered from the grid), conditioning the value of the ground resistance. In this case and to obtain acceptable results, models with different dimensions and node numbers have to be proven to evaluate the availability of the application, needing a lot of time and memory of the computer. Another additional problem was the value of the boundary conditions to be applied for the size of the considered model.

To avoid these problems, a new method [7] was developed, allowing the determination of the ground resistance starting from the dissipated power, or from the stored energy by the electric field. The method had the additional advantage of being independent of the value of the boundary conditions, shape and size of the mesh and kind of soil.

Such a method, offers very important improvements to calculate the ground resistance and the step and touch voltages because uses reduced models (short earth distance) but doesn't resolve the problem of a reduced node number in the interface between the ground electrode and the soil, lowering the precision of the method. To reduce this problem we will apply the finite element method to 3D solid models.

\section{Method}

The main advantage of the simulation of the grounding system behaviour using the finite element method, by means of 3D solid models, in relation with the traditional models in $2 \mathrm{D}$ or $3 \mathrm{D}$, is the real and geometrical simulation of the grounding grids. Consequently the method may be applied for every grounding grid kind, with independence of the geometry (diameter of the ground electrode, number and size of the meshes, number of ground rods and soil configuration).

For the ground resistance calculation, an infinite earth and flat surface is supposed. In these conditions, all the equipotential surfaces, far from the ground grid, are supposed to be spherical.

In accordance with the indicated previously, the ground resistance can calculate like sum of two resistances.

$$
\mathrm{R}_{T}=\mathrm{R}_{1}+\mathrm{R}_{2}
$$

Where:

$\mathrm{R}_{1}$ : ground resistance of a semi-sphere with radius $d_{1}$ (see figure 1). Being $d_{1}$ the earth distance for which the distribution of potentials can be supposed spherical.

$R_{2:}$ ground resistance between $d_{1}$ and infinite.

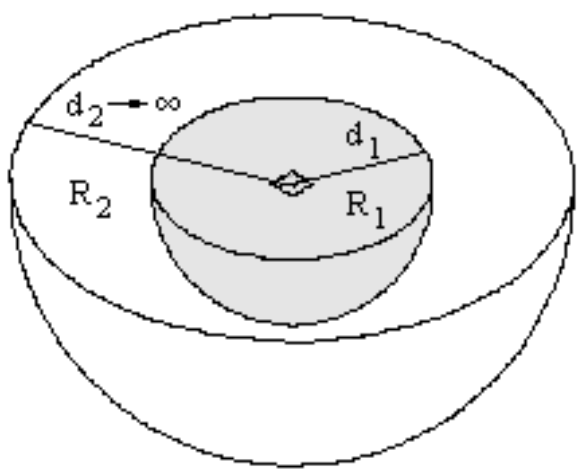

Figure 1. Model

The $R_{1}$ resistance can be calculated using the finite element method, simulating the grounding grid behaviour by means of 3D solid models, previous calculation of the dissipated power (carrying out a current flow analysis).

For an arbitrary geometry, the resistance between two electrodes can be expressed, in term of electric field, as follows:

$$
R=\frac{\int_{L} \mathbf{E} \cdot \mathbf{d l} \mathbf{l}}{\int_{S} \sigma \mathbf{E} \cdot \mathbf{d} \mathbf{S}}
$$

Where:

S surface that surrounds completely to an electrode.

$\mathrm{L}$ any trajectory that join both electrodes.

E electric field.

$\Sigma$ conductivity.

In general, it's more advisable the calculation of the ground resistance starting from the dissipated power, by means of the following expression:

$$
\mathrm{R}_{1}=\frac{(\text { grid potential })^{2}}{\text { dissipated power }}
$$


The losses are determined with the following expression:

$$
\mathrm{P}=\int_{V} \mathbf{E} \cdot \mathbf{J} \mathrm{dV}=\int_{\mathrm{V}} \sigma \mathrm{E}^{2} \mathrm{dv}
$$

Considering that the ground resistance only depends on the soil constitution and grid geometry, the boundary potential can be arbitrary.

The resistance $R_{2}$ can be calculated applying the expression (2) to calculate the resistance of a semispherical resistor of $\mathrm{d}_{1}$ internal radium and infinite external radium. In these conditions the expression (2), is transformed in the following expression [8]:

$$
\mathrm{R}_{2}=\frac{1}{2 \pi \sigma} \cdot\left(\frac{1}{d_{1}}\right)
$$

Figure 2 shows the mesh utilised to analyse the grid 3 of the table I.
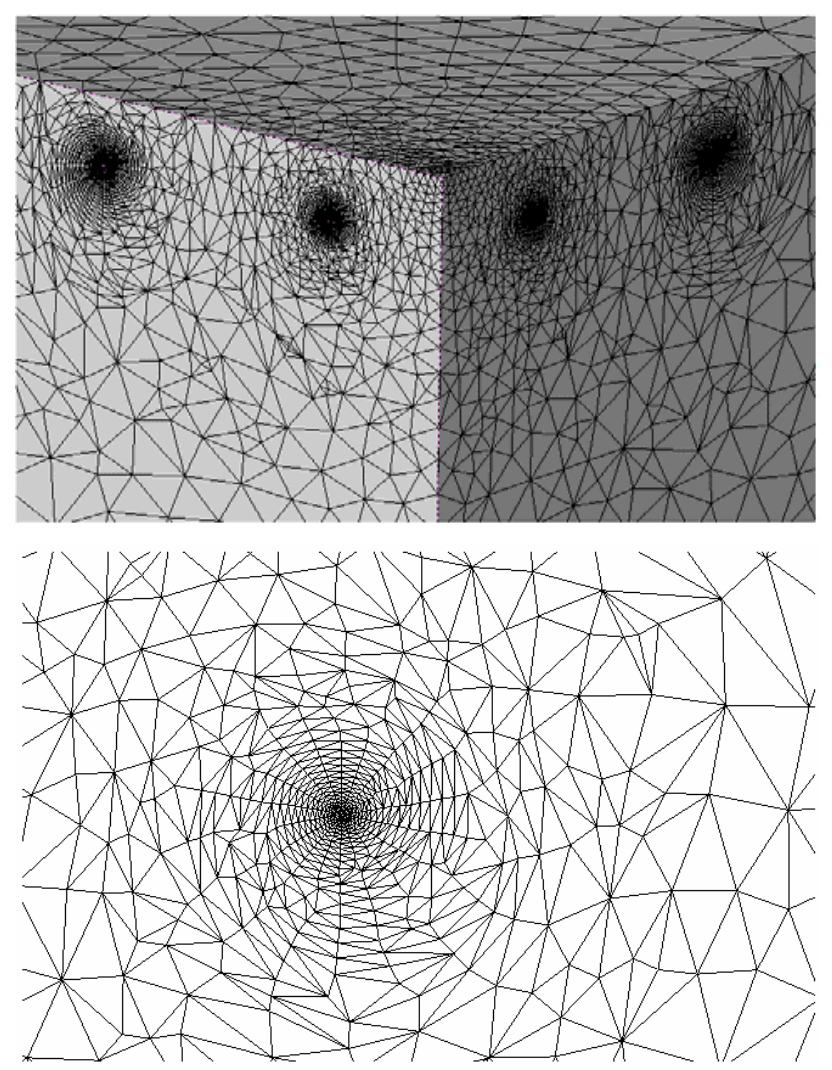

Figure 2. Mesh (zoom)

Once the ground resistance and the earth fault current are known, it can be determined: a) the grid potential and b) the touch and step voltages. The touch and step voltages can be obtained:

- Directly, measuring the nodal potentials in the finite element model, or preferably

- Using our own program, in C language, which reads the potentials in the different nodes of the model and valuate the points where the touch and step voltages are maximum.

\section{Results}

\section{A. Ground resistance}

The proposed method described in the previous section has been applied to calculate the ground resistance of square or rectangular grids indicated on table I.

TABLE I. - Ground resistance of grid of different shapes Conductivity of soil $=0.01 \Omega^{-1} \mathrm{~m}^{-1}$

Depth of burial $=0.5 \mathrm{~m}$

Diameter of conductor $=10 \mathrm{~mm}$

Number of meshes $=\mathrm{n}$

Dimensions of grid $=a, b$ meters

\begin{tabular}{|c|c|c|c|c|}
\hline Grid & $\mathrm{N}$ & $\mathrm{a}(\mathrm{m})$ & $\mathrm{b}(\mathrm{m})$ & Resistance $(\Omega)$ \\
\hline 1 & 1 & 2 & 2 & 19.12 \\
\hline 2 & 4 & 8 & 2 & 9.56 \\
\hline 3 & 9 & 6 & 6 & 6.26 \\
\hline 4 & 15 & 10 & 6 & 5.14 \\
\hline 5 & 25 & 10 & 10 & 3.74 \\
\hline 6 & 3 & 12 & 4 & 6.84 \\
\hline 7 & 8 & 16 & 8 & 4.21 \\
\hline 8 & 16 & 16 & 16 & 2.78 \\
\hline 9 & 18 & 24 & 12 & 2.8 \\
\hline 10 & 20 & 20 & 16 & 2.57 \\
\hline 11 & 2 & 10 & 5 & 7.22 \\
\hline 12 & 6 & 15 & 10 & 4.07 \\
\hline 13 & 12 & 20 & 15 & 2.83 \\
\hline 14 & 18 & 30 & 15 & 2.37 \\
\hline 15 & 20 & 25 & 20 & 2.17 \\
\hline 16 & 4 & 20 & 20 & 2.6 \\
\hline 17 & 8 & 40 & 20 & 1.96 \\
\hline 18 & 15 & 50 & 30 & 1.42 \\
\hline 19 & 25 & 50 & 50 & 1.03 \\
\hline 20 & 35 & 70 & 50 & 0.91 \\
\hline
\end{tabular}

The obtained error in all the analysed grids is less than $12 \%$.

Also, the following grid configuration has been studied

A) $12 \mathrm{~m} \times 8 \mathrm{~m}$ grounding grid, with $8 \mathrm{~m} \times 6 \mathrm{~m}$ meshes and 6 ground rods of $2 \mathrm{~m}$, buried at a depth of $0.6 \mathrm{~m}$ in a soil stratified in two layers. First layer has a depth of $0.2 \mathrm{~m}$ and $1 / 3000 \Omega^{-1} \mathrm{~m}^{-1}$ soil conductivity and the second layer with $1 / 22 \Omega^{-1} \mathrm{~m}^{-1}$ soil conductivity.

B) $2,5 \mathrm{~m} \times 6 \mathrm{~m}$ grounding grid, with $1.25 \mathrm{~m} \times 2.25 \mathrm{~m}$ meshes and 6 ground rods of $2 \mathrm{~m}$, buried at a depth of $0.7 \mathrm{~m}$ in a soil stratified in two layers. First layer has a depth of $0.015 \mathrm{~m}$ and $1 / 6000 \Omega^{-1} \mathrm{~m}^{-1}$ soil conductivity and the second layer with $0.053 \Omega^{-1} \mathrm{~m}^{-1}$ soil conductivity.

The obtained results are shown in Table II.

TABLE II. - Resistance ground

\begin{tabular}{|c|c|c|}
\hline Grid & Method proposed $(\Omega)$ & Experimental measures $(\Omega)$ \\
\hline A & 0.98 & 1.00 \\
\hline B & 2.40 & 2.50 \\
\hline
\end{tabular}

Taking into consideration these last results, we can see that in all cases the mistakes made using the method exposed in this paper are less than $8 \%$. 
The soil resistivity has been measured using the Wenner's method and the ground resistance using the method of the two auxiliary ground rods.

\section{B. Potencial distribution in the soil.}

Once we have determined the ground resistance and the earth fault current is known, we can determinate de distribution of potential in the soil.

Figure 3 shows the distribution of potentials in the soil, has been the model were analysed (grid 3 of the table I).

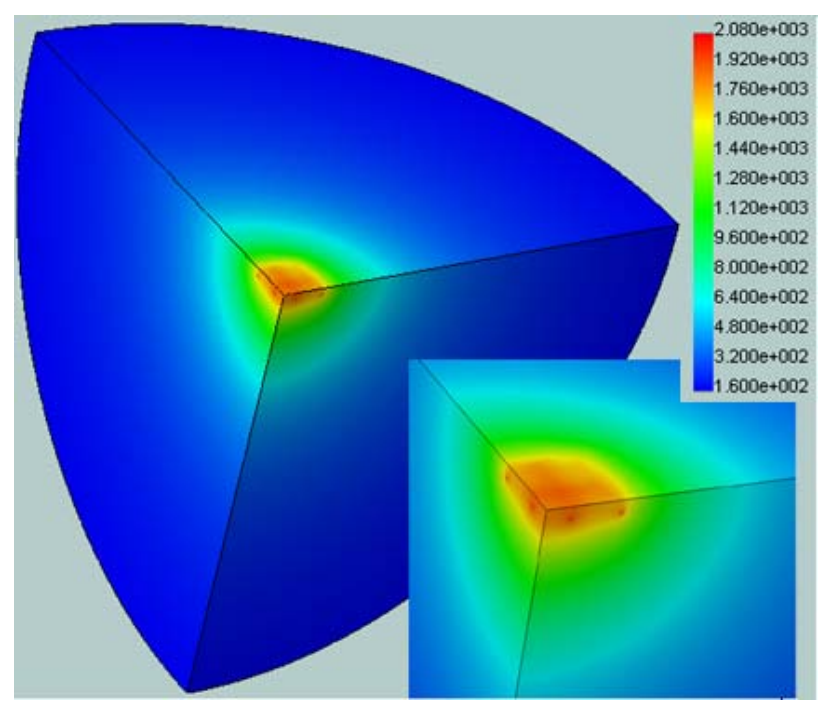

Figure 3. Potential distributions (V)

Figure 4 shows the potential variation with the distance (measured starting from centre of the grid) according to the $\mathrm{x}$ axis and diagonal of the grid and when the earth fault current is of $300 \mathrm{~A}$.

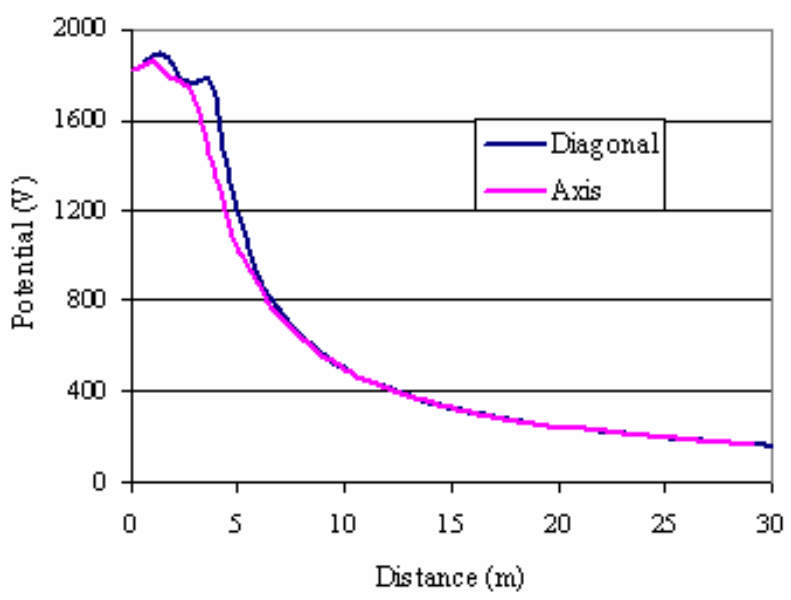

Figure 4. Potential curves in the soil surface

\section{Conclusion}

A new method for the ground resistance calculation using finite element method has been presented in this paper.

The results obtained, by means of method presented in this paper, are sufficiently good if are compared with those experimentally measured or calculated by other methods.

The method herein exposed is independent of the grid geometry and soil configuration.

The method developed in this paper is based on the independence of the ground resistance respect to the earth fault current, being independent of the value of the boundary condition and the arbitrary potential assigned to the grid.

The method is mainly indicated for the calculation of ground resistance in asymmetric grids and/or in stratified soils with multiple layers.

Once the ground resistance and the earth fault current are know, the potentials in the nodes of the surface of the soil and the touch and step voltages can be calculated.

\section{References}

[1] B. Thapar, V. Gerez, A. Balakrishnan and D. A. Blank, "Evaluation of a grounding grid of any shape", IEEE Trans. on Power Delivery, Vol. 6, No. 2, pp. 640-645, April 1991.

[2] F. P. Dawalibi and D. Mukhedkar, "Optimum design of substation grounding in two-layer earth structure", IEEE Trans. Power Apparatus and Systems, Vol. PAS-94, No, 2, pp. 252-272, April 1975.

[3] H.R. Seedher, J.K. Arora and B. Tapar, "Finite expressions for computation of potential in two layer solid", IEEE Trans. on Power Delivery, pp. 1098-1102, 1987.

[4] H.S. Lee, J.H. Kim, F.P. Dawalibi and J. Ma, "Efficient ground grid designs in layered soils", IEEE Trans. On Power Delivery, Vol. 13, No. 3, pp. 745-751, July 1998.

[5] B. Thapar. and S.L.Goyal., "Scale model studies of grounding grids in Non-uniform soils". IEEE Trans. on Power Delivery, Vol. 2, pp. 1060-1066, October 1987.

[6] T. Takahashi and T. Kawase, "Calculation of earth resistance for a deep-driven rod in a multi-layer earth structure", IEEE Trans. On Power Delivery, Vol. 6, No. 2, pp. 608-614, April 1991,

[7] J.A. Güemes, F.E. Hernando, "Cálculo de redes de tierra utilizando el método de elementos finitos. Comparación de resultados", in Proc. I IEEE Andean Región Internatinal Conference, Vol. 2, pp. 902-906, 1997.

[8] M. Zahn, Teoría Electromagnética, Interamericana, México, D.F (1987), pp.169-173.

[9] Q. Meng, J. He, F.P. Dawalibi and J. Ma, "A new method to decrease ground resistances of substation grounding systems in high resisistivity regions", IEEE Trans. On New Power Delivery, Vol. 14, pp. 911-916, 1999.

[10] J. Jin, "The finite element method in electromagnetics", John Wiley \& Sons, New York (1993). 